\title{
Risk in The Construction Industry
}

\author{
Haytham Baraka ${ }^{1 *}$, Mostafa $\mathrm{H}$ Kotb $^{2}$ and Moustafa Ismail Abu Dief ${ }^{3}$ \\ ${ }^{1}$ Zagazig University, Egypt \\ ${ }^{2}$ Azhar University, Egypt \\ ${ }^{3}$ Certified Forensic Claims Consultant, Egypt
}

*Corresponding author: Haytham Baraka, Zagazig University, Egypt.

Received Date: April 22, 2019

Published Date: May 06, 2019

\begin{abstract}
Risk is inherent in each project in the construction industry in various forms. It can be a threat, which has a negative impact on the project objectives. On the other hand, it can also be an opportunity, which has a positive impact, or a business risk that has a negative or positive impact. This paper provides a brief about risk in the construction industry, risk definition and types of risks. Moreover, it provides an overall view of risk management processes.
\end{abstract}

Keywords: Risk; Management; Threat; Construction; Project objective; Impact; Uncertainty

\section{Introduction}

All over the world today, the construction industry is the main engine of development, social welfare, and national economy. It contributes greatly to the jobs market by providing many jobs and in different specialization such as Engineers, Accountants, different labors and many other titles. Additionally, with regard to the urban and industrial development, it supports both by providing the feasibility studies, conceptual design, cost estimate, construction and maintenance services. Therefore, we agree that construction deserves more attention and researches in order to decrease the uncertainty as much as possible, which will maximize the likelihood of achieving the objectives of the different projects within the construction industry. Uncertainty range differs from project to another based on the project's circumstances. There are many sources of uncertainty and on the other, hand, we can manage this uncertainty by using some tools and processes. Uncertainty comes from the undefined scope, undefined project objectives, project constraints, improper design, ambiguous contract, and other unknowns. This uncertainty is always translated into risks because both are causing events with a probability of less than $100 \%$, which is defined as a risk.

The above discussion indicates that there are some tools and processes to manage risk either proactively or reactively. By the way, the difference between proactive and reactive can be summarized at the time of managing the risk. If we manage the risk before occurring, definitely it's a proactive approach. On the other hand, the reactive approach is managing the risk after occurring. Risk management is a collaborative effort to drive the project forward the targeted success through some processes. It's not means or aim to avoid all project risks. Definitely, it aims to determine the probable events and maximize the probability or the impact of opportunities and minimize the probabilities or the impact of the threats. Every day, the construction parties are requested to make decisions, which definitely have great impacts on their project. Risk management is very important to make an informed decision. An informed and proactive decision means basing the decision on clear information even it includes an amount of uncertainty.

\section{Risk definition}

A risk is a probable event that has a probability, a cause or more and an impact or more. Usually, the probability is not a fixed number and it's changed along the project period. It may be very high at a time and becomes very low at another time based on the project circumstances. The cause of risk is something that converts the probability of occurring into a hundred perfect. It may be one cause and may be a group of causes. Furthermore, the occurred risk may represent a cause for another risk. Also, the response of the risk may represent a cause for a new risk which called a secondary 
risk. The impact of the risk can be positive or negative or a mix between both. The highest number of risks are mostly existed on the initiation phase because of the big uncertainty, after that the uncertainty begins to be decreased along the project period because of the information received noted through the execution phase.

\section{Risk Names according to the time of Risk Identification}

Each project passes through some phases until reach the closure phase. The project phases are initiation, planning, execution, monitor and control, and closure. Risks are may be discovered at any phase and it can be identified ether before taking placing or after that. Accordingly, one of the risk classifications is mainly based on the identification times as follows:

\section{Known risk}

A known risk is a risk identified during planning processes, and it can be identified during the execution phase but before occurring. Therefore, the identified contractual risk is considered as known risks. It can be assessed and planned proactively. Normally, we can't predict all probable risks for many reasons such as lack of experience; uncertainty; lack of information; unexpected changes; enterprise environmental factors.

\section{Unknown risk}

Unknown risk is an undiscovered risk until during the planning phase or execution phase. It cannot be managed pro-actively unless identifying it before occurring. In addition, it can be discovered and planned it discovered before the occurrence.

\section{The new risk or discovered risk}

Risk has been discovered during the control risk process, which is under the execution phase, and before it's occurring.

\section{Secondary risk}

A risk, which results from a response plan of another risk, and identified during the planning of risk response.

\section{Residual risk}

A risk which is identified during the planning process and accepted. In most cases, these risks have a low impact on the project.

\section{Risk Sources}

The risk sources are various and are changed over the project duration. In other words, it can be categorized into internal sources and external sources. For more clarification, internal source means those which under the project manager control, while the external source is outside the project manager control. External sources such as economic conditions, political conditions, legal, natural hazards, social conditions, and natural environments. On the other hand, internal sources such as the construction technology, and human factors risk.

\section{Risk Breakdown Structure}

Identified risk must be categorized in order to manage it effectively and also facilitate discovering more probable risks.
It's very helpful to determine the root causes of risk, effective response, the interaction between risks and well understand the project's risks. It also considered as a powerful tool to identify risk, so it commonly used in the risk identification process. The most important use of categories is that it allows risk to be organized well and also can help to tailor responses to deal with a category in a more effective way rather than dealing with individual risk. Many authorities and authors exposed to this point and developed various categories of risks. All categories aimed to classify the identified risks in an organized way based on different considerations. For instance, risks may be categorized based on the root causes of risks, project phase, impact, rank, responsibility, and other methods. Seung H Han \& James E Diekmann [1] Classified construction risks into five categories, namely: political, economic, cultural/legal, technical/ construction and other risks. JG Perry \& RW Hayes [2] pointed the sources of the various risks and then classified the risks in terms of risks retainable by client, contractor, consultant. Dale Cooper \& Chris Chapman [3] classified risks as per their nature and magnitude and grouped risks into two major types are primary risks and secondary risks. Tah JHM, et al. [4] classified risks based on their origin and the location of the impact of the project site. Risk breakdown structure is a hierarchical way to organize the identified risk through a number of levels starts from a high-level title and go to a more detailed level which presents the project risks. It is developed during the planning phase and updates as needed during the control phase. In this essay, risks will be classified based on the party who shall bear the risk according to the contract. So, the main categorizes of risks are contractor risks and client risks. The classification is more helpful the address the problem of this research and supports the main objective which is to highlight the risk in each contract and how shall bear it.

\section{Risk Management Process}

Risk management can be managed in two ways are formal and informal. The informal management of risk is to manage risk not following a specific process. Usually, in this case, the contractor allows contingency either a fixed amount or a percentage to absorb any arise risks during construction. It's clearly seen that this way does not need effort but it`s very risky and doesn`t support the decision making. Moreover, it does not alert the project manager toward the probable risks. The formal way to manage risk is comprised of some processes that will control the project's risk. These processes are varying from company to another and also from the author to another. According to PMI [5], there are six processes to manage risk are:

1. Planning risk management

2. Risk identification

3. Qualitative risk assessment

4. Quantitative risk assessment

5. Plan risk response

6. Monitor risk 
These processes are iterative which means it will be done several times along the project.

\section{Conclusion}

Risk is existed in each project especially the construction industry due to the big amount of complexity and uncertainty. Theses risk has several and various impacts on the project objectives ranging from high impact and low impact, therefore it shall be managed closely and deeply. Risk management can be managed in two ways are formal and informal. The informal management of risk is to manage risk not following a specific process. Usually, in this case, the contractor allows contingency either a fixed amount or a percentage to absorb any arise risks during construction. It's clearly seen that this way does not need effort but it's very risky and doesn't support the decision making. Moreover, it does not alert the project manager toward the probable risks [6-11].

\section{Acknowledgment}

First and foremost, praise and thanks be to Allah the Great and Almighty for enabling me in fulfillment the present work. I am grateful to Prof. Dr. Mostafa H. Kotb, Prof of Structural Engineering, Dr. Moustafa Ismail Abu Dief for their scientific supervision, great assistance, sincere guidance, and their endless advice during the accomplishment of the present work. Finally, I would like to give my deepest thanks to my parents, my wife, and my family for their continued encouragement during my study.

\section{Conflict of Interest}

No conflict of interest.

\section{References}

1. Seung H Han, James E Diekmann (2001) Approaches for Making Risk-Based Go/No-Go Decision for International Projects. Journal of Construction Engineering and Management 127(4).

2. JG Perry, RW Hayes (1985) Risk and its Management in Construction Projects 78(3).

3. Dale Cooper, Chris Chapman (1987) Risk Analysis for Large Projects: Models, Methods, and Cases. Wiley; $1^{\text {st }}$ edn.

4. Tah JHM, Thorpe A, McCaffer R (1996) Risk interdependicies and natural language computations. Journal of Engineering, Construction and Architectural Management.

5. PMI (2017) PMBOK® Guide ( $6^{\text {th }}$ edn).

6. AACE International (2018) AACE® International Recommended Practice No. 10S-90, Cost Engineering Terminology.

7. Billows D (2011) Project Qualitative Risk Analysis. The Hampton Group, Inc.

8. Leroy Doris, Neil Opfer, Sean T Regan, Ted Turner (2013) Decision and Risk Management Professional ${ }^{\mathrm{TM}}$ (DRMP) ${ }^{\mathrm{TM}}$ (1 $1^{\text {st }}$ edn.) (C. C. Sean T. Regan, Ed.) AACE $®$ International.

9. Martin L, John R, Charles R, David H (2006) Risk Management in Projects ( $2^{\text {nd }}$ edn.). Taylor \& Francis.

10. PMI (2009) Practice Standard for Project Risk Management. Project Management Institute.

11. US Office of the Secretary of Defense (2006) Risk Management Guide for DOD Acquisition ( $6^{\text {th }}$ edn. Version 1.0). US Department of Defense. 